\title{
Formação de professores de Educação Infantil e Anos Iniciais do Ensino Fundamental: a experiência de validação de objetos de aprendizagem
}

\author{
Prof. a Dr. ${ }^{a}$ Patrícia Alejandra Behar; NUTED/UFRGS; pbehar@terra.com.br
}

Msc. Daisy Schneider; NUTED/UFRGS; daisy.schneider@gmail.com

$\mathrm{Msc}^{\text {anda }}$. Caroline Bohrer do Amaral; NUTED/UFRGS; carolinebohrer82@yahoo.com.br

Ana Paula Frozi de Castro e Souza; NUTED/UFRGS; nanafrozi@ yahoo.com.br

Resumo. As novas demandas da Educação Infantil referem-se a um novo tipo de infância decorrente do advento da informática: a ciberinfância. Desta forma professores precisam confrontar suas práticas com novas formas de se trabalhar, valorizando a não-linearidade de conteúdo e o trabalho a partir da perspectiva do aluno. O presente artigo apresenta o percurso para a validação dos objetos de aprendizagem Ciberinfância, Arquiteturas Pedagógicas para a Educação Infantil e Produzindo Infâncias, através de um curso de formação de professores de Educação Infantil e Anos Iniciais do Ensino Fundamental.

Palavras-chave: formação de professores, educação, objetos de aprendizagem

\section{Kindergarten's and Initials Years of the Elementary School's teacher training: the validation experience of learning objects}

\begin{abstract}
The new demands of kindergartens refer to a new type of childhood arising from the advent of computers: the cyber-childhood. Thus teachers must confront their practices with new ways of working, while the non-linearity of content and work from the perspective of the student. This article presents the route for the validation of the learning objects Cyber-childhood (Ciberinfância), Teaching Architectures for Kindergartens (ArquiteturasPedagógicas para Educação Infantil) and Producing Childhoods (ProduzindoInfâncias) through a training course for kindergartens' and Initials Years of the Elementary School's teachers.
\end{abstract}

Key-words: training teachers, education, learning objects 


\section{Introdução}

Atualmente, os objetos de aprendizagem (OA) apresentam-se como uma alternativa para disponibilização de conteúdos de forma mais dinâmica e atraente. Por esse motivo, o grupo de pesquisa no qual os autores do presente estudo fazem parte, tem realizado estudos para o desenvolvimento desses materiais, enfocando a formação de professores da Educação Básica. Nesta perspectiva, através do projeto "Produzindo Professores de Educação Infantil para a EAD e a Cibercultura"1 foram desenvolvidos três objetos, são eles: (1) Ciberinfância - o qual apresenta temáticas referentes às novas demandas desta infância, (2) Arquiteturas Pedagógicas para Educação Infantil - abordando o planejamento e sua articulação com os recursos tecnológicos e (3)Produzindo Infâncias - o qual enfoca a produção das infâncias na atualidade. Estes fizeram parte de uma dissertação de Mestrado em Educação ${ }^{2}$, na qual foram levantadas as necessidades para que estes pudessem responder à demanda dos professores desta etapa da educação.

O principal objetivo deste projeto foi contribuir para a atualização e reflexão dos professores em serviço, viabilizando a aplicação das tecnologias digitais na realidade escolar. Portanto, para a validação dos objetos de aprendizagem, foi oferecido um curso para a construção de arquiteturas pedagógicas na Educação Infantil. Assim, buscou-se colaborar para a ampliação das discussões sobre infância, informática na educação e planejamento em AVA na perspectiva da arquitetura pedagógica. Os desafios disponibilizados nos objetos foram aplicados em aulas do curso de extensão a serem oferecidos à comunidade acadêmica e escolar. Os objetos de aprendizagem, o qual teve como público-alvo os professores de Educação Infantil em exercício, bem como os alunos do curso de Pedagogia e do Curso de Especialização em Educação Infantil.

A seguir, são apresentadas algumas características dos OA desenvolvidos pelo grupo, uma descrição do curso de extensão, bem como, os resultados obtidos através da aplicação dos objetos.

\section{Objetos de aprendizagem}

Objeto de Aprendizagem é qualquer recurso digital como, por exemplo: textos, animação, vídeos, imagens, aplicações, páginas Web em combinação que se destinam a apoiar o aluno no processo de aprendizagem. São recursos digitais modulares, usados para a apoiar a aprendizagem presencial e à distância. Os OAs podem ser reutilizados em ambientes virtuais de aprendizagem ou mesmo em sites para educação, aprendizagem e treinamento, tanto presencialmente, quanto a distância (IEEE, 2005; Wiley, 2000 apud Tarouco, 2006). Essa perspectiva visa, entre outros fatores, reduzir o custo na produção de materiais pedagógicos, gerando interesse dos educadores, inclusive na sua construção.

Através da pesquisa na Web, podem ser agregados materiais gratuitos e livres ao objeto com facilidade, como também reutilizar outros, adaptando-os ao seu contexto educacional. De qualquer forma, o planejamento é fundamental na produção dos OA. Para isso, segundo Amante e Morgado (2001) deve-se tratar, primeiramente, da concepção do projeto que consiste na seleção da idéia/tema, da equipe, dos conteúdos, dos objetivos pedagógicos, do público-alvo, do tipo de aplicação e do contexto. Em seguida, deve-se partir para a planificação (seleção e organização dos conteúdos, mapa 
geral do objeto, interface, navegação, storyboard, ajustes). Por fim, faz-se necessário implementar (desenvolvimento propriamente dito) e avaliar o material. Os objetos de aprendizagem, para serem considerados como tal, devem permitir acesso e uso em locais e plataformas diferentes, neste último caso, sem necessidade de reformulação (Fabre et al, 2003 apud Tarouco et al, 2004). Outra vantagem de se utilizar os objetos para desenvolver conhecimentos/conteúdos é a possibilidade de acoplar recursos multimídia, tais como som, imagem, vídeo, simulações etc. Esses recursos dinamizam a forma de apresentação e de manipulação dos conteúdos, possibilitando outras possíveis construções de conhecimento pelos sujeitos.

Nesta perspectiva, entende-se que este recurso pode auxiliar o professor em sua ação docente, pois oferece diferentes ferramentas que servem de apoio ao processo de aprendizagem. A utilização de elementos multimídia, tais como simulações, imagens, textos, som, animações e vídeos, desempenham um papel importante na aquisição de conhecimento quando bem utilizadas. Estes podem ser considerados como recursos pedagógicos que permitem ao aluno acompanhar o conteúdo de acordo com o seu próprio ritmo, acessando facilmente a informação e se engajando de forma independente e autônoma num aprendizado por descoberta. As ferramentas comunicacionais, como por exemplo: chats, fóruns de discussões, e-mails e blogs potencializam o processo de interação entre sujeitos, aumentando o grau de envolvimento das pessoas e, como conseqüência, elevam o grau de conscientização sobre o próprio processo de desenvolvimento cognitivo e a relação deste com o contexto social.

Os objetos de aprendizagem desenvolvidos neste estudo foram desenvolvidos em Flash 8 e possuem recursos como vídeos, textos, guia do professor, desafios entre outros. Os materiais encontram-se disponíveis nos sites $^{3}$ dos grupos de pesquisa participantes do projeto e em DVD, para quem não tem acesso à Internet. Da mesma forma, estão cadastrados em um repositório para multiplicar as discussões e o conhecimento sobre essas temáticas e torná-las reusáveis. Nesse repositório não há necessidade de seguir um padrão determinado, apenas se deve preencher um formulário eletrônico com as especificações do material.

\section{1 Objeto de Aprendizagem Ciberinfância}

A Ciberinfância é tema de reportagens e parte da preocupação de professores e de pais, o que foi evidenciado também no curso de extensão. Portanto, o objetivo pedagógico da exploração desse tema para um OA é discuti-lo através de aspectos, tais como a história das infâncias, os aspectos socioculturais e da área da saúde e suas relações com a sociedade informatizada. Dessa maneira, a finalidade foi dar subsídios para reflexão sobre as práticas pedagógicas na Educação Infantil.

A interface gráfica do OA é uma sala com objetos que compõem lan houses, quartos infantis e salas de escolas de Educação Infantil, como mostra a figura 1 da tela inicial. Nessa metáfora procurou-se contemplar os lugares por onde as crianças ou os ciberinfantes transitam.

Os desafios, em um total de sete, são os seguintes: TICs (Tecnologias da Informação e da Comunicação); Saúde e Computador; Computador, Infância e Escola; Prós e Contras (do uso do computador pelas crianças); História da Infância; Ciberinfância; e Projeto (trabalho final). Esses desafios são compostos, basicamente, de 
materiais escritos em forma de texto, hipertexto ou em apresentação de slides. Os modos de avaliação abrangem atividades (pesquisas, crônicas, comentários, artigos, memoriais, projetos) em diferentes ferramentas, tais como blog, webnote, fórum, editor de slides, entre outros, além da sugestão de uso do ambiente virtual de aprendizagem.

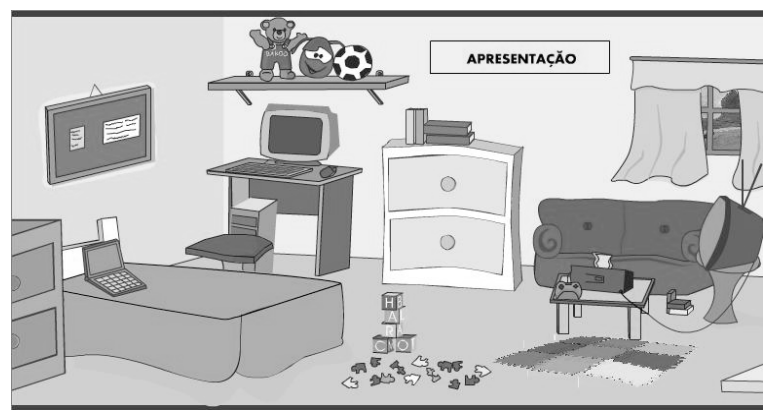

FIGURA 1 - Tela Inicial OA Ciberinfância

\subsection{Objeto de Aprendizagem: Arquiteturas Pedagógicas para Educação Infantil}

A compreensão sobre o que significa "arquitetura pedagógica" é fundamental para o uso de AVAs na Educação. O modo como o professor com o apoio do computador pode indicar uma prática baseada em um planejamento, interligando o recurso informático aos projetos da turma ou em um "espontaneísmo", mostrando-se descontextualizada do trabalho de sala de aula. Esse OA teve o objetivo de discutir planejamento pedagógico na Educação Infantil, ambientes virtuais de aprendizagem e arquiteturas pedagógicas, bem como possibilitar a compreensão sobre as Arquiteturas Pedagógicas (APs) e sua aplicação no fazer pedagógico na Educação Infantil.

Para discutir esse tema, estruturou-se o OA Arquiteturas Pedagógicas para Educação Infantil em módulos, quais sejam, Educação Infantil, Ambientes Virtuais de Aprendizagem e, finalmente, Arquiteturas Pedagógicas. Cada módulo apresenta um desafio sobre o que significa o respectivo assunto e outro acerca de como trabalhá-lo. Sugeriu-se que o AVA construído pelo mesmo grupo de pesquisa pudesse ser uma alternativa para a interação e publicação das produções, quando o objeto estiver inserido/integrado na proposta de uma disciplina.

A metáfora da interface gráfica foi representada por uma escola. Ao "entrar" nela, encontra-se um corredor com três portas destinadas a cada módulo, os quais podem ser explorados livremente, mas se indica no Guia, que o usuário realize primeiro os módulos Educação Infantil e Ambientes Virtuais de Aprendizagem, a fim de que haja melhor compreensão sobre o tema das APs. O material de apoio e o glossário aparecem de forma permanente no menu do objeto. Nos módulos encontra-se o link "Depósito de Ferramentas" o qual possui indicações de softwares, AVAs e lista de "links interessantes". Já o "Vídeo" apresenta todos os vídeos inseridos no OA para serem acessados a qualquer tempo. 


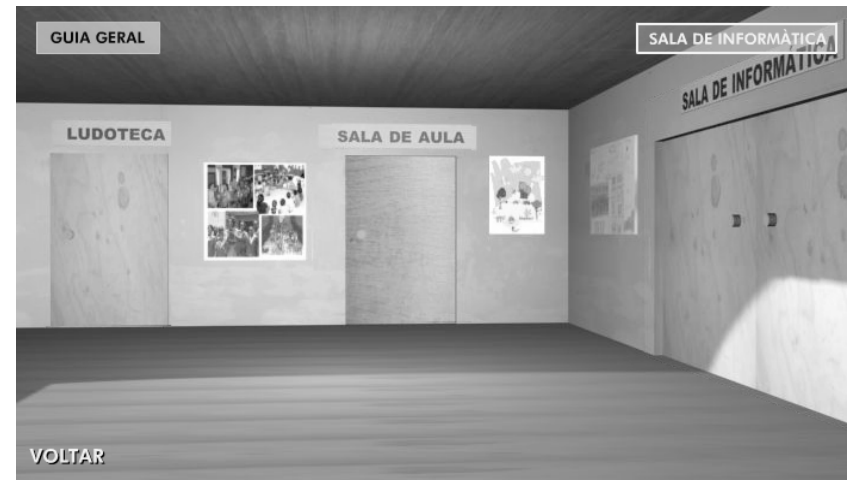

FIGURA 2 - Tela Inicial OA Arquiteturas Pedagógicas para Ed. Infantil

\subsection{Objeto de Aprendizagem: Produzindo Infâncias}

As contribuições e demandas das professoras durante o curso de extensão oferecido pelo grupo de pesquisa permitiram refletir sobre o tema "produção das infâncias". Sendo assim, buscou-se debater nesse material questões históricas, sociais, culturais e políticas que, de alguma forma, produzem as infâncias. Com isso, pode-se colaborar para a reflexão sobre aspectos que surgem nas rotinas com crianças e que apontam a constituição de diferentes infâncias.

Na metáfora buscou-se criar um cenário que remetesse a essa produção na contemporaneidade por meio da interface gráfica composta de um baú iluminado. Desse baú saem fotos de crianças com objetos/situações (antigos e novos), que podem produzir as infâncias. As telas dos elementos que compõem o objeto seguem o mesmo padrão de interface, utilizando cor de destaque às palavras importantes.

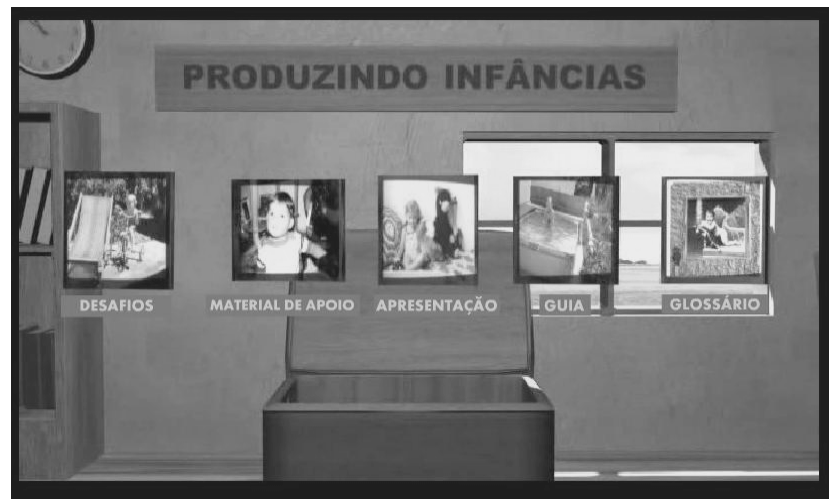

FIGURA 3 - Tela Inicial OA Produzindo Infâncias

3. Validação dos objetos de aprendizagem: curso de extensão “Oficina de Arquiteturas Pedagógicas para Educação Infantil"

A validação dos objetos de aprendizagem consistiu na realização de um curso de extensão no Laboratório de Informática do Ensino Superior (LIES/FACED/UFRGS), baseado nos pressupostos da pesquisa participante. Fizeram parte da população pesquisada professores de educação infantil da rede pública e privada, professores do primeiro ano do Ensino Fundamental de nove anos e uma professora do Curso Normal. Trata-se de um estudo qualitativo que tem como metodologia a pesquisa participante, em que os dados foram levantados a partir dos registros das contribuições dos alunos no 
AVA Planeta ROODA. Portanto, a metodologia de pesquisa tinha como foco a uma formação de professores acerca da construção de arquiteturas pedagógicas para Educação Infantil. Dessa forma, buscou-se compreender as concepções e demandas dos professores pesquisados acerca do uso das TIC's na escola e como o curso de extensão poderia ajudá-los a articular o trabalho com o computador e os projetos desenvolvidos em sala de aula.

A proposta de construção de Arquiteturas Pedagógicas (AP's) para educação infantil visa à contextualização do trabalho com o computador na sala de aula, de modo que este não seja apenas um brinquedo, mas um recurso pedagógico. Para isso, propôsse tratar a linguagem informática como mais uma das múltiplas linguagens, nas quais as crianças de educação infantil estão inseridas. O trabalho com as múltiplas linguagens nesta etapa da educação permite o estabelecimento de redes de relações, nas quais permitem aos alunos reestruturar suas significações anteriores, produzir boas diferenciações e construir outras/novas significações. De acordo com este paradigma, não basta utilizar os recursos informáticos, é preciso problematizá-los e produzir novas relações numa pedagogia reflexiva. Assim, o conhecimento passa a ser produto de interação individual e interindividual que ocorre através de trocas afetivas, respeito mútuo, investimento de interesses, valores e tomada de consciência (SCHNEIDER, 2007).

A Pesquisa Participante (PP) foi escolhida para esta pesquisa devido ao seu caráter educacional, social, informal e dialético. Trata-se de uma pesquisa qualitativa, portanto, parte-se da observação dos fenômenos e dos sujeitos no ambiente social e histórico em que são produzidos, restabelecendo o cotidiano enquanto espaço no qual estes se manifestam. Nessa modalidade de pesquisa, os dados coletados são analisados a partir da descrição das concepções que a população pesquisada apresenta, quanto ao tema em questão (Behar et al. 2004). Neste estudo, pretendeu-se mobilizar os professores para o desenvolvimento do processo investigativo, a fim de que estes se tornassem agentes de transformação em seu meio social e não mais expectadores dela. Nesse paradigma, ressalta-se a importância deste tipo de pesquisa no campo da educação por sua ação transformadora, visto as demandas educativas no país. Assim, tanto os pesquisadores poderiam "ensinar" sobre as arquiteturas pedagógicas, quanto os professores sobre suas práticas e experiências e concepções de infância. Esta etapa compôs-se da elaboração/realização do curso de extensão (montagem de conteúdo e páginas HTML, observação participante/diário de campo, coleta de registros nas funcionalidades).

Para a coleta de dados, foi realizado o curso de extensão que abordou os seguintes temas: (1) Ambientes Virtuais de Aprendizagem (AVA's) e os espaços digitais, (2) ciberinfância - a geração dos nativos digitais, (3) instituições de Educação Infantil - como estas instituições estão lidando com esta nova demanda e estratégias para pensar a educação da ciberinfância, e (4) a construção de arquiteturas pedagógicas para a educação infantil, articulando o planejamento e os recursos digitais. $\mathrm{O}$ curso contou com a participação de 9 professoras, sendo delas de Educação Infantil, duas de $1^{\mathrm{o}}$ ano do Ensino Fundamental e uma professora do Laboratório de Informática do Curso Normal, em uma escola da rede estadual.

A escolha do AVA Planeta ROODA se deu com o intuito de que, após o curso, as professoras/alunas pudessem utilizar-se deste recurso para a montagem de suas Arquiteturas Pedagógicas. As aulas foram ministradas presencialmente com o suporte V. 6 № 1 , Julho, 2008 
do AVA Planeta ROODA, especificamente as funcionalidades: Fórum e Bate-papo (ambos para interação entre todo o grupo), Diário (para reflexões das alunas sobre seu processo de aprendizagem no curso), Projetos (trabalhos em grupo e publicação de arquivos), Biblioteca (publicação das aulas e de leituras complementares) e Contatos (comunicação por e-mail). O AVA possibilitou um registro das discussões entre os participantes do curso e a familiarização com este espaço digital.

As temáticas foram trabalhadas a partir dos objetos de aprendizagem já citados e seus respectivos textos e desafios. Assim, estes foram usados como módulos do curso. Montou-se o curso de forma que cada temática fosse trabalhada em um dia de aula, com atividades a distância no decorrer da semana. Cada aula possuía um texto inicial, desafios, interações virtuais/presenciais e leituras. Parte das pesquisadoras ministravam as aulas com auxílio de uma graduanda de Pedagogia que realizava a monitoria.

A coleta de dados constituiu-se dos registros no AVA das discussões e reflexões das professoras/alunas, do diário de campo acerca das questões mais importantes de cada encontro e as observações participantes junto à turma. O objetivo central desta etapa da pesquisa visava discutir e refletir sobre propostas de planejamento pedagógico que contextualizassem o uso das TIC's na Educação infantil, através do curso de extensão por meio da formação de professores.

\subsection{Análise e discussão dos dados}

A metodologia utilizada para a análise dos dados foi a Análise de Conteúdo proposta por Moraes (1999), com o intuito de realizar a análise das ações dos sujeitos. Tal metodologia propõe um conjunto de fundamentos e procedimentos específicos para a análise de dados qualitativos. Segundo o autor, a análise de conteúdo é uma interpretação pessoal por parte do pesquisador com relação à percepção que este tem dos dados. Atualmente, a ênfase desta metodologia está tanto no processo como no produto, considerando o emissor, o receptor e contexto da mensagem. Nesta análise devem ser consideradas as formas de codificação e de transmissão das mensagens através da ação, fala e escrita (Moraes, 1999).

A conversão/unitarização do conteúdo dos dados em unidades de análise, possibilitou a criação de categorias. A categorização tem como objetivo classificar as unidades levantadas durante o estudo, verificada através da ação dos sujeitos. Nesta perspectiva, foram definidas três categorias de análise, com algumas subcategorias. Tal processo foi constituído por um movimento dinâmico/recursivo de leituras, no qual realizou-se a análise dos dados. Nesta perspectiva foram definidas três categorias: (1) TIC's na Educação Infantil - apresenta as contribuições dos sujeitos pesquisados acerca das possibilidades de uso das TIC's na Educação Infantil e que estratégias de trabalho podem ser construídas; (2) Arquiteturas Pedagógicas - agrupa as evidências referentes ao planejamento e à construção das AP's propriamente ditas; (3) Formação de professores - refere-se à defasagem na formação e suas dificuldades na utilização das TIC's.

Nas falas dos professores registradas no ambiente virtual, pôde-se observar que o curso proporcionou reflexões acerca da ação pedagógica junto à ciberinfância como uma prática que deve envolver o uso das tecnologias e da linguagem informática, mas sem esquecer das múltiplas linguagens na Educação Infantil. Portanto, é importante compreender a criança como um agente social, que interpreta seu mundo e sua vida de 
forma particular, através de múltiplas interações simbólicas estabelecidas pelas crianças entre si, com adultos e com os espaços digitais.

Os espaços digitais da ciberinfância podem ser entendidos como os recursos informáticos que permitem interação e comunicação. Por permitirem a interação entre sujeito-objetos, como também entre os próprios sujeitos, estas ferramentas têm inúmeras possibilidades educativas. Essas foram pensadas e verbalizadas pelas professoras/alunas quando se iniciou o trabalho com as arquiteturas pedagógicas, mais ao final do curso. Acredita-se que isso se deve à compreensão devido à própria vivência no decorrer do curso em um espaço digital. Tal vivência tornou-se significativa, a medida que as professoras/alunas apropriavam-se de seus espaços digitais e davam-se conta deles no decorrer do curso. De acordo com Nevado (2004), quando a formação do professor enfatiza a sua experiência, este passa a incorporar a inovação que lhe foi apresentada, buscando transformar a sua prática de modo significativo. Logo, as vivências das professoras/alunas nos espaços digitais das crianças e a dinâmica dos desafios dos objetos a partir de sua prática contribuíram para que ocorressem mudanças significativas na maneira de pensarem sua prática em sala de aula, como pode-se observar a seguir.

Penso que a infância que nós encontramos em sala de aula é uma infância variada, plural, diversificada. Crianças muito diferentes umas das outras, algumas com muita tecnologia a sua disposição, outras com a experiência das ruas na vida. Olhar e perceber suas diferentes experiências faz parte do nosso trabalho de professor atualmente. Esta infância nos exige mais mobilidade mental para oferecer um espaço adequado a elas. Acredito que estas crianças que tem acesso à internet podem contribuir de várias maneiras em sala de aula, mas destacaria dois pontos: em primeiro seu pensamento não linear, sua capacidade de pensar, refletir e associar vários assuntos ao mesmo tempo; também o livre acesso a informação, contribuiem muito mais na troca de dados com os colegas. Sem dúvida, nossa prática pedagógica necessita de reflexões e muita flexibilidade; precisaremos repensar nossas atitudes e deixar de centralizar nossas práticas em torno de nós professores. Será preciso abrir mais espaço com estas crianças.

$$
\text { N.R.A. - Fórum }
$$

Sarmento (2007), coloca que as crianças incorporam, interpretam e reconstroem continuamente suas informações culturais, constituídas por diversos elementos com os quais a criança interage. Nessa perspectiva, os objetos auxiliaram as professoras a compreenderem as outras infâncias e culturas presentes em sua sala de aula. Assim, foi possível pensar novas formas de se trabalhar com estas crianças e como formular uma ação pedagógica que responda à ciberinfância.

A reflexão na ação, através do uso dos objetos de aprendizagem, permitiu às professoras/alunas refletir e confrontar o seu conhecimento prático anterior com situações novas, podendo assim criar novas perspectivas sobre o seu trabalho e sua ação docente. Nesta perspectiva, a prática configurou-se como um processo que se abre para a reflexão sobre quais devem ser os fins e qual o significado das situações em sala de aula (Contreras, 2002), como pode-se verificar na tabela abaixo.

Creio que podemos dizer que as possibilidades pedagógicas [com os espaços digitais] são infinitas! O que mais me fascina em ver meus alunos ( $1^{\circ}$ ano com $6 / 7$ anos de idade) trabalhando na internet é justamente a autonomia que eles vão adquirindo, as escolhas 
que vão fazendo e o quanto vão cada vez menos precisando de meu auxílio! Fico maravilhada em ver o grande crescimento e progresso de uma para outra aula. Toda esta construção e autonomia levam consigo para a sala de aula convencional e para sua vida em geral, tornando-se pessoas mais abertas, dinâmicas, questionadoras, etc. É claro que podemos usá-los na Educação Infantil. É maravilhosos vê-los navegando e escolhendo por si mesmos os rumos que irão tomar!

Sim concordo, a única coisa que temos que cuidar perante nossos alunos é em relação a linguagem e escrita, pois vejo que aos poucos esta se perdendo e eles estão construindo uma linguagem nova que na maioria das vezes nem sabemos o que significa, então temos que cuidar para que isso acabe trazendo resultados ruins pra vida deles.

A. B. - Fórum

\subsection{Resultados}

Neste estudo, foi possível constatar não só a importância da formação dos professores para a construção de Arquiteturas Pedagógicas, mas como motivação proporcionada pelo uso de objetos de aprendizagem influenciou no rendimento, ou até mesmo na procura por um curso de formação. Portanto, a partir desta experiência, pode-se concluir que a utilização dos objetos na formação dos professores os auxiliou a refletir de forma mais profunda sobre suas práticas e conceitos intrínsecos na ação pedagógica. Tal reflexão se faz necessária, na medida em que a construção de AP exige do professor novos olhares sobre o planejamento, os alunos, seu papel como professor e sua prática. Como resultados desta pesquisa, também pode-se citar o engajamento por parte de professores em sua aprendizagem. A participação no curso com autonomia e adquirindo uma postura crítica frente ao uso da informática na educação deve-se também à estratégia pedagógica empregada nos $\mathrm{OA}$.

Os resultados imediatos e significativos desta pesquisa devem-se, de certa forma, pelo perfil do grupo. Este foi constituído por professoras já alfabetizados digitalmente e que estavam costumadas a usar as TIC na sua prática pedagógica. Outra questão levantada a partir da análise dos dados foi o porquê deste perfil de professoras buscando um curso de formação. A hipótese levantada é de que, por serem mais familiarizadas com as tecnologias, sentiram-se mais seguras em buscar uma formação. Outra questão é a maioria das professoras serem advindas da rede pública de ensino, na qual, muitas vezes, não há profissionais especializados para o trabalho no laboratório, ao contrário da maior parte das escolas da rede privada.

\section{Considerações Finais}

O material disponível nos objetos ficou organizado por temática, incluindo os conteúdos e os desafios a respeito. Além disso, ampliou-se a dimensão de possibilidades de informação e reflexão, na medida em que os recursos contribuíram para isso. Nos objetos de aprendizagem descritos nesse artigo proporciona-se entrar em contato com idéias de várias fontes sobre os temas debatidos, inclusive, de especialistas por meio das entrevistas na forma de vídeos e textos.

Também, visou-se a organização das produções dos alunos que trabalharam com estes objetos, propondo espaços virtuais para armazenamento de arquivos. Nesses espaços, como um ambiente virtual de aprendizagem, por exemplo, é possível realizar discussões e troca de idéias para dinamizar a construção do conhecimento. 
Uma interface onde se reconheceram elementos semelhantes às temáticas desenvolvidas proporcionou uma navegação mais intuitiva por parte dos usuários dos OA. Do mesmo modo, teve-se como finalidade organizar as informações a fim de facilitar a realização tanto de um trabalho na forma de hipertexto, como de uma forma linear. Dessa forma, o usuário do objeto possui autonomia para escolher qual dessas formas se adapta melhor a sua metodologia de trabalho.

Portanto, através deste estudo, foi possível constatar que os objetos de aprendizagem desenvolvidos atingiram os objetivos propostos no projeto "Produzindo Professores de Educação Infantil para a EAD e a Cibercultura". Nesta perspectiva, o grupo tem mantido o padrão de atividades desafiadoras e priorizando a navegação não linear nos OA. Pretende-se que, por meio do estabelecimento dessas linhas mestras na construção de objetos de aprendizagem, seja possível criar um padrão para a construção de objetos de aprendizagem interativos.

\footnotetext{
Notas

${ }^{1}$ Fomentado pelo Edital SEAD 2005/5, da Universidade Federal do Rio Grande do Sul UFRGS.

2 SCHNEIDER, Daisy. PLANETA ROODA: desenvolvendo arquiteturas pedagógicas para Educação Infantil e Anos Iniciais do Ensino Fundamental. Dissertação de Mestrado.- Porto Alegre: UFRGS, 2007.

${ }^{3}$ NUTED - http://www.nuted.edu.ufrgs.br/ei e GEIN - http://www.ufrgs.br/faced/gein

${ }^{4}$ Arquitetura Pedagógica é o resultado da articulação entre o planejamento pedagógico do professor, o recurso tecnológico, podendo ser um AVA, Wiki ou outro espaço digital e os conteúdos, que podem ser trabalhados a partir de softwares ou objetos de aprendizagem.
}

\section{Referências Bibliográficas}

AMANTE, L. e MORGADO, L., Metodologia de Concepção e Desenvolvimento de Aplicações Educativas: o caso dos materiais hipermedia, In: Discursos: língua, cultura e sociedade. Portugal: 2001, v. 3, n. especial, p. 27-44.

CONTRERAS, José. A autonomia de Professores. - São Paulo: Cortez, 2002.

MORAES, Roque. Análise de Conteúdo. In: Revista Educação. Porto Alegre. № 37. Março, 1999.

NEVADO, Rosane A. Novos Possíveis na formação de professores. In: FRANCO, Sérgio R. K. (org.) A Informática na Educação: estudos interdisciplinares. - Porto Alegre: Editora da UFRGS, 2004.

SARMENTO, Manuel J. Cultura Infantis e Interculturalidade. In: DORNELLES, Leni Vieira. Produzindo Pedagogias interculturais na infância. Petrópolis, RJ: Vozes, 2007. 
SCHNEIDER, Daisy. PLANETA ROODA: desenvolvendo arquiteturas pedagógicas para Educação Infantil e Anos Iniciais do Ensino Fundamental. Dissertação de Mestrado.- Porto Alegre: UFRGS, 2007.

TAROUCO, L. Objetos de Aprendizagem para M-Learning In: Anais do Congresso Nacional de Tecnologia da Informação e Comunicação, Brasil, http://www.cinted.ufrgs.br/CESTA/objetosdeaprendizagem_sucesu.pdf, Setembro, 2004.

TAROUCO, L. Objetos de Aprendizagem, In: FÓRUM EAD, Brasil, http://www.ufrgs.br/sead/arquivos/objetosdeaprendizagem_liane.pdf, Setembro, 2006.. 